\title{
Micro-crystallography comes of age
}

\author{
Janet L. Smith ${ }^{1}$, Robert F. Fischetti ${ }^{2}$, and Masaki Yamamoto ${ }^{3}$ \\ ${ }^{1}$ Life Sciences Institute and Department of Biological Chemistry, University of Michigan, Ann \\ Arbor, MI 48109 USA \\ ${ }^{2}$ Advanced Photon Source, Argonne National Laboratory, Argonne, IL 60439 USA \\ ${ }^{3}$ RIKEN SPring-8 Center, 1-1-1 Koto, Sayo-cho, Sayo-gun, Hyogo, 679-5148 Japan
}

\begin{abstract}
The latest revolution in macromolecular crystallography was incited by the development of dedicated, user friendly, micro-crystallography beamlines. Brilliant X-ray beams of diameter 20 microns or less, now available at most synchrotron sources, enable structure determination from samples that previously were inaccessible. Relative to traditional crystallography, crystals with one or more small dimensions have diffraction patterns with vastly improved signal-to-noise when recorded with an appropriately matched beam size. Structures can be solved from isolated, well diffracting regions within inhomogeneous samples. This review summarizes the technological requirements and approaches to producing micro-beams and how they continue to change the practice of crystallography.
\end{abstract}

\section{Introduction}

Macromolecular crystallography is being transformed by the rapidly growing use of microcrystallography. Micro-crystallography, coupled to novel data collection instruments and strategies, was developed to analyze crystals smaller than a few tens of microns $(\mu \mathrm{m})$ to address many challenging and scientifically important problems. A highly brilliant X-ray beam of equivalent size is optimal for measurement of diffraction data from such microcrystals [1]. Compared to conventional macromolecular crystallography experimental stations [2], micro-crystallography beamlines target samples smaller than $20 \mu \mathrm{m}$ and beam sizes in the range of $1-20 \mu \mathrm{m}$ [3]. Such micro-beams enhance the diffraction signals from micro-crystals by reducing background scattering from solvent and the sample support, thus providing high signal-to-noise in diffraction images [4]. Micro-beams can also address a variety of sample imperfections by illuminating only a well diffracting region within an imperfect crystal or a single-crystal region of a multi-crystal sample. Because many biological macromolecules and complexes yield small or clustered or inhomogeneous crystals, early successes at micro-crystallography beamlines spurred a huge demand for beam time and additional micro-crystallography capacity.

Small and highly brilliant X-ray beams suitable for micro-crystallography are available at third-generation synchrotron radiation facilities due to their low-emittance electron beams $(<10 \mathrm{~nm} \mathrm{rad})$ and coupled insertion devices. Modern undulators produce X-ray beams with brilliance on order of $10^{20}$ photon $/ \mathrm{mm}^{2} / \mathrm{mrad}^{2} / 0.1 \% \mathrm{BW}$ (yielding $10^{12}$ photon/sec or more

\footnotetext{
(C) 2012 Elsevier Ltd. All rights reserved.
}

Publisher's Disclaimer: This is a PDF file of an unedited manuscript that has been accepted for publication. As a service to our customers we are providing this early version of the manuscript. The manuscript will undergo copyediting, typesetting, and review of the resulting proof before it is published in its final citable form. Please note that during the production process errors may be discovered which could affect the content, and all legal disclaimers that apply to the journal pertain. 
in a $20-\mu \mathrm{m}$ beam at the sample position) in the energy range of 5-35 keV (wavelength 2.5$0.35 \AA$ ). The advent of brilliant undulator radiation coincided with the widespread use of cryo-protection for protein crystals, enabling use of the new brilliant X-ray beams for conventional macromolecular crystallography (beams of $50 \mu \mathrm{m}$ or larger). Together these advances set the stage for micro-crystallography. The early successes in microcrystallography were from pioneering experiments at ESRF beamline ID13 [5,6,7,8], where macromolecular crystallography shared time with a variety of other experiments requiring a micro-focus beam. The ID13 micro-beam was critical for several structure determinations before the turn of the century (reviewed in [7]), and led others to develop a micro-beam capability on beamlines dedicated to macromolecular crystallography $[9,10,11,12,13,14,15]$.

Several high-profile successes $[16,17,18,19,20,21]$ published since the last microcrystallography review in this journal [22] have opened up exciting areas of research where previously no tractable crystals existed. Micro-crystallography was key to solving all crystal structures of G-protein-coupled receptors (GPCR) reported in the past five years. Taken together, these structures are a major breakthrough in our understanding of how receptors respond to stimulation at the cell surface $[17,19,20,23,24]$ and how receptor stimulation signals a cascade of events leading to an altered physiological state within the cell [21]. GPCRs and many other membrane proteins form notoriously small, weakly diffracting, radiation-sensitive crystals that can yield high-resolution structures in a micro-beam while being intractable to large-beam crystallography. Virus polyhedra are naturally occurring micro-crystals that enclose infectious insect viruses. Micro-crystallography provided highresolution structures that explain the stability of the polyhedra under extreme environmental conditions except those favorable to infection $[18,25,26]$. Micro-crystallography has also provided fundamental insights into the structural basis for the high stability of the amyloid fibrils and toxic oligomers associated with many devastating diseases [16,27].

These successes along with the greater availability of micro-beams led to a rapidly growing demand that currently exceeds the capacity of the world s operating micro-crystallography beamlines. Here we summarize the critical features of micro-crystallography beamlines and the change in experimental practice that they are driving in structural biology.

\section{Technologies for micro-crystallography: It's all about stability}

The essential technologies that enable micro-crystallography are a high-stability and lowdivergence beam from the storage ring, X-ray optics to create a micro-beam of high brilliance and stability, and a sample environment of high stability and precision including the diffractometer and sample-visualization system. Stability of the beam intensity and the relative alignment of the beam and crystal are paramount in micro-crystallography. Typical exposure times for diffraction images at modern crystallography beamlines range from a few seconds to a few tens of milliseconds with a fast-framing detector. Therefore, fluctuations on time scales of $0.01-200 \mathrm{~Hz}$ can result in decreased signal-to-noise through loss of incident intensity and therefore diffracted intensity and/or increased background resulting from beam motion. These fluctuations can originate from instabilities in the particle beam, front end, beamline optics and endstation equipment. The greatest success in achieving high-quality data from micro-crystals comes from a holistic approach to the beamline that considers everything from the particle beam along the X-ray beam path to the detector.

Factors that affect particle beam stability include day and night temperature changes in the storage ring tunnel, the tides and X-ray thermal load on components. For example, a $1^{\circ}$ change in temperature causes an $11-\mu \mathrm{m}$ expansion of a $1-\mathrm{m}$ steel rod. One important development that improved beam stability is the "Top-Up" mode of operation $[28,29]$ that maintains a constant beam current, thereby stabilizing the temperature of the tunnel and all 
support structures in the front end. The incorporation of high-resolution X-ray beamposition monitors in positional feedback systems at some facilities has also improved beam stability.

On the beamline, environmental factors such as temperature and vibration contribute to beam instability. Most crystallography beamlines employ either a channel-cut or a doublecrystal monochromator (DCM), which must provide a stable output beam under varying thermal load conditions. Channel-cut monochromators are less sensitive to vibrations and thermal load variation than are DCMs; however, energy changes require realignment of the entire beamline downstream of the monochromator. Loss of parallelism of the two crystals of a DCM, caused by thermal transients, can result in a slow drift of beam position and intensity at the sample position. Without correction, the beam position can drift by several microns over a few hours, which is a serious problem for beam and sample sizes less than 10 $\mu \mathrm{m}$. The constant heat load on the optics in "Top-Up" mode significantly reduces the thermal drift. Vibrations of monochromator crystals cause high-frequency instability, which usually can be overcome by appropriate mechanical design, especially vibration dampening and vibration control of the circulating coolant [10,30]. Long-term instability can usually be reduced by the use of a fine positional feedback loop slower than $10 \mathrm{~Hz}[31,32,33,12]$. Simple, heavy, stiff mechanisms of all optical components and granite support tables can provide great stability to environmental temperature changes and vibrations.

As the beam and crystal size are diminished, sample mounting, manipulation and visualization become more difficult, and the instrumentation must maintain a micron-sized crystal within a beam of similar dimensions for the duration of the experiment. The widely accepted target for the precision and stability of the interception of the beam and the crystal is one-tenth of the crystal or beam size, whichever is smaller. A decade ago, most macromolecular crystallography beamlines were designed for beam and crystal sizes of order $100 \mu \mathrm{m}$, requiring $10-\mu \mathrm{m}$ stability, which was readily achieved with good mechanical design. Reduction of the crystal and focal spot size to $10 \mu \mathrm{m}$ or even $1 \mu \mathrm{m}$ presents increasing technical challenges. The requisite $1-\mu \mathrm{m}$ stability for a $10-\mu \mathrm{m}$ beam can be achieved by robust mechanical engineering to minimize vibrations and thermal fluctuations in the beamline optics and experimental enclosure [10,12,34,35]. Similarly, a $1-\mu \mathrm{m}$ beam or crystal requires stability of $100 \mathrm{~nm}$, and another order-of-magnitude improvement in stability and precision, including maintaining the endstation environment at a constant temperature to within $\sim 0.1^{\circ} \mathrm{C}[13]$.

In addition, the visualization axis must coincide with the X-ray beam and must be aligned to the sample with similar accuracy and precision $[6,13,36]$. A high-performance microscope with sub-micron resolution (near the diffraction limit for visible light) is needed to precisely position samples and adjust the beam focus at the sample position. A microscope that is coaxial with the X-ray beam minimizes parallax errors [8], and is also useful for beam position monitoring with a high-resolution scintillation target mounted at the sample position.

'Sub-micron' precision goniometry is extremely challenging for instruments with a horizontal rotation axis due to gravity effects on the mechanisms for crystal rotation and translation, and currently is not possible for a multi-axis goniometer with, for example, kappa geometry. The peak-to-peak sphere-of-confusion (SOC) at the beamlines profiled below ranges from $3.0 \mu \mathrm{m}$ to $0.4 \mu \mathrm{m}$ (Figure 3). Air-bearing goniometers under development promise even smaller SOC values. Instruments with a vertical rotation axis avoid gravity effects, and should permit use of multi-axis kappa geometry.

Robotic sample handling improves stability by reducing temperature fluctuations from frequent openings of the enclosure door and inadvertent bumps of the goniometer and beam- 
delivery hardware by experimenters. Additionally, sample automounting saves time as large numbers of crystals generally must be screened in order to find a high-quality crystal or to identify regions of a crystal or field of crystals with suitable diffraction [37,38,39]. Robotic systems for sample handling have become standard equipment at most crystallography beamlines, and a variety of micro-crystallography-compatible sample changers have been developed [40,41,42,43,44,45].

Sample cryo-cooling can contribute to temperature gradients in the experimental hutch. Careful venting of cold stream gas is a requirement for all micro-crystallography experiments.

\section{Approaches to making a small beam}

Approaches of four types have been implemented to achieve a small beam at the sample position (Figure 1). The choice for any beamline depends on the effective emittance of the source (product of the horizontal size and divergence), and the tradeoff between intensity and convergence in the beam. Micro-crystallography has been enabled by a steady emittance decrease at most synchrotrons, so that all four approaches can provide a micro-beam with a focal convergence in the range $0.1-1.5 \mathrm{mrad}$, as needed for typical unit cell dimensions and mosaicity of macromolecule crystals.

All four approaches to a small beam (Figure 1) are in use at successful beamlines. Here we profile one example of each approach. Table 1 is a summary of operating microcrystallography beamlines and those in various stages of development.

The four profiled beamlines have several features in common. During the design and commissioning phases, considerable attention was given to ensuring a high degree of beam positional and intensity stability. The first optical component on all the beamlines is a highstability monochromator where the number of motorized motions was reduced and turbulence in the circulating liquid nitrogen coolant was minimized to avoid exciting vibrations. The focusing optics are mounted on granite plinths to minimize vibrations. Accelerometers were used to detect vibrations and guide mechanical design improvements. The endstations incorporate high resolution, on-axis microscopes to visualize and optically center crystals measuring only a few microns on edge. Each of the endstations is maintained at a constant temperature within $1^{\circ} \mathrm{C}$ or less. Exhaust from the sample cryo-cooler is transported away from the sample environment, and heat sources in the experimental enclosure are kept to a minimum.

APS beamline 23-ID-D, for both traditional and micro-crystallography, is an example of the "aperture" approach (Figure 1a), which uses focusing optics to condense the beam followed by a beam-defining aperture near the sample position (Figure 2). To meet the stringent requirements of a micro-crystallography beamline, the DCM has undergone continuous modification [46]. A pair of bendable "bimorph" mirrors arranged in the Kirkpatrick-Baez (KB) geometry image the undulator source to $25 \times 65 \mu \mathrm{m}^{2}$ at the sample position. The long mirrors (1050 $\mathrm{mm}$ horizontal and $600 \mathrm{~mm}$ vertical) collect the full central cone from the undulator. A quad-mini-beam collimator has user-selectable 5, 10 and $20 \mu \mathrm{m}$ diameter beam-defining apertures for micro-crystallography and a $300 \mu \mathrm{m}$ scatter guard aperture for traditional crystallography (Figure 2b) [11,47]. The beam-defining aperture defines a smaller, more Gaussian beam at the expense of flux, although it preserves the central flux density of the beam. The minimum achievable beam size is limited to $\sim 5 \mu \mathrm{m}$ by the availability of small apertures and the beam convergence angle. Alignment of the beam and the rotation axis is stable for $\sim 24$ hours. Beam movements on the aperture are observed as intensity drift or fluctuations [34], which can be corrected by an automatic feedback system. The RMS intensity fluctuation is $1-2 \%$ for the $5-\mu \mathrm{m}$ beam. A key element to the beamline 
success is the rapidly (seconds) changeable beam size, and software to fully exploit the small beam sizes [37].

ESRF beamline ID23-2, dedicated to micro-crystallography, is an example of the "directfocus" approach (Figure 1b), which relies on highly demagnifying optics to focus the beam directly to the desired size at the sample position. At ID23-2, the monochromator incorporates a single, side-bounce crystal that defines the fixed operating energy [12]. A pair of short $(300 \mathrm{~mm})$ mechanically bent, mirrors arranged in the KB geometry focus the beam to a standard focal size of $7.5 \times 7.5 \mu \mathrm{m}^{2}$, but it can be slightly smaller. Here flux is lost because the focusing optics intercept only part of the undulator beam. A thermostatic enclosure around the mirror system is key to minimizing beam drift at the sample to less than $5 \mu \mathrm{m}$ in 24 hours. Advantages of the direct-focus approach compared to the aperture approach are the shorter, i.e. less expensive, mirror optics; a shorter lever arm from the optic to the sample, which reduces sensitivity to slope error, mirror drift or vibrations; and smaller intensity fluctuations. However, to change the beam size, the mirror focus must be shifted downstream, which is a slow process (tens of minutes).

SPring- 8 beamline BL32XU, dedicated to crystals of dimension $10 \mu \mathrm{m}$ or smaller, is an example of the "divergence-limited source" approach (Figure 1c) where highly demagnifying optics image a source point defined by slits in the divergent undulator beam. BL32XU (Figure 3) has the world s first 1- $\mu \mathrm{m}$ beam dedicated to macromolecular crystallography [13]. Following a high-precision DCM, an aperture of variable size creates the divergence-limited source, from which the beam is focused onto the sample using fixedcurvature, elliptical mirrors. To achieve a sub-micron focus, the mirror surfaces were fabricated to atomic-scale accuracy by Elastic Emission Machining (EEM) [48,49]. By changing the aperture size, the beam size can be varied rapidly (seconds) up to $10 \mu \mathrm{m}$ with a minimum of $0.9 \times 0.9 \mu \mathrm{m}^{2}$ (Figure 3a). A recently developed micro-diffractometer with an air-bearing rotation axis and linear XY positioners has sub-micron precision of rotation, i.e. a sphere-of-confusion (SOC) of $<0.4 \mu \mathrm{m}$ (Figure 3b,c). The endstation is enclosed in a chamber within the experimental enclosure where the temperature is controlled to $0.1^{\circ} \mathrm{C}$ to maintain a high degree of positional stability. The first diffraction image with $d_{\text {min }} \sim 2 \AA$ was collected from an illuminated volume of $1 \times 1 \times 2 \mu \mathrm{m}^{3}$ in a $5 \times 5 \times 2 \mu \mathrm{m}^{3}$ protein crystal (K. Hirata, personal communication).

DLS beamline I24 supports traditional and micro-crystallography, and is an example of using upstream optics to create a "secondary-source" (Figure 1d), which is then imaged to the sample position by a second set of optics [9]. A DCM selects the energy, and bimorph mirrors arranged in the KB geometry create an image of the undulator source several meters upstream of the sample position. Slits at this position define a spatially clean secondary source. A second set of KB mirrors creates an image of the secondary source at the sample position. By imaging a rigidly supported secondary source point, this approach provides beam stability at the sample position by decoupling from fluctuations in the source (position and angle) and in the upstream optics. The secondary source slits and second set of KB mirrors can be translated along the beamline to vary the focal demagnification, resulting in variable beam size at the sample position with constant intensity, effectively an "X-ray zoom". When fully commissioned, beam size changes will take several minutes by zooming, and, at the expense of flux, more rapidly by varying the slit size. A key feature of this beamline is the combination of shutterless data collection and sample rastering, which significantly reduces the time to map out the quality of a large crystal or to locate microcrystals [38].

The aperture, divergence-limited-source and secondary-source approaches have the operational convenience of rapid (seconds) selection of the beam size by varying a slit or 
aperture size, but at the cost of variable flux. In contrast, the direct-focus approach and the secondary-source zoom require a slower refocusing of the mirrors (several minutes), but can provide a constant integrated flux over various beam sizes and aspect ratios. A major advantage of the secondary-source zoom approach is the combination of a constant integrated flux and a focus maintained at the sample position, thereby minimizing any delirious effects from structure in the beam. As designed, the demagnification ratio of the beamlines increases from roughly 10:1 for 23-ID-D to 20:1 for ID23-2 to 30:1 for BL32XU. The higher demagnification ratios can lead to higher flux density at the focal position and also increased divergence, depending on what portion of the undulator central cone is accepted. The demagnification ratio on I24 is the product of the ratio for the first and second stages of focusing and varies from about 10:1 to 20:1.

\section{Practice of micro-crystallography}

The trend towards micro-crystallography is driving a fundamental change in the practice of macromolecular crystallography. Because single-crystal regions of samples no longer must have length many tens of microns, far more samples are screened relative to data sets collected, far more data sets are constructed from multiple crystals or from multiple regions of one crystal, and far more crystals now produce useful data that formerly were relegated to the dustbin. The shift in acceptable sample quality drives the rapidly growing demand for beam time at micro-crystallography stations. Where it is robust, user-friendly and available routinely, micro-crystallography has become the new normal.

What aspects of the nebulous quality of "user friendliness" are key to the success of microcrystallography beamlines? Advances on the beamlines, together with improvements in the emittance properties and stability of storage-ring particle beams, deliver X-ray beams of high flux and low divergence to the sample. To be user friendly for micro-crystallography, a beamline must have beam and sample positional stability that is robust enough for users to rapidly tailor the beam size to the sample without need for beam realignment. If microcrystallography is to be the new normal, beam tailoring without realignment must also include energy changes. Equally important are software tools for users to search quickly within the sample for the best diffracting regions, and to record diffraction images from all useful parts of the sample $[39,37,38]$. Compared to large-beam crystallography, fewer unit cells of the crystal are illuminated in micro-crystallography, a greater X-ray flux is delivered to a smaller sample volume, and radiation damage per illuminated volume is greater in each diffraction image. However, since a smaller crystal volume is damaged per diffraction image, software tools that spread X-ray exposure through the sample during data collection can effectively mitigate radiation damage. Schemes for "vector" or "helical" data collection have been quite successful [12,37].

Successful micro-crystallography beamlines are driving new technologies in sample handling, crystallogenesis and data collection. Two developments have especially high impact and may lead to further fundamental changes in practice. Meso-phase crystallization of membrane proteins has matured after many years of incubation $[50,51,52]$ and resulted in spectacular success with several important membrane-protein crystal structures. Crystals grown in the lipidic cubic phase are generally small and are often difficult to see visually due to opacity of the lipid at the temperatures of sample cryo-protection $(100 \mathrm{~K})$. For these samples, software for a raster or grid search is essential to find well diffracting regions within a field of small crystals. Another exciting development is the ability to record diffraction data from crystals in their growth chamber, known as in situ diffraction [53,54]. This can be of enormous importance in screening crystallization conditions to distinguish crystals from non-crystalline solids as well as macromolecule crystals from salt or lipid crystals. However, it also promises to segue into a routine method for data collection where 
single (or a few) diffraction images are recorded from each crystal. The first structures solved with in situ data were published this year [55]. In situ diffraction is necessarily done at the temperature of crystal growth, i.e. samples are not cryo-protected. Recent exciting evidence suggests that damage from radiation-generated free radicals can be "outrun" by use of fast-readout detectors [56,57].

A fundamental change on the horizon is a return to the practice of multi-crystal data collection, which was standard before crystal cryo-protection techniques were developed. Multi-crystal data sets are needed to achieve statistically significant diffracted intensity when extreme radiation damage results from large doses to micro-volumes [17,52] or to enhance a weak phasing signal [58]. New software tools for data processing, and especially for assembly of complete data sets from a large number of partial data sets, are under development in several labs and will become increasingly important as microcrystallography and in situ diffraction become more widespread and as more focused beams of even greater flux are developed.

\section{Radiation damage}

Radiation damage is a major consideration in micro-crystallography because many fewer unit cells are illuminated than in large-beam crystallography, and consequently a greater Xray dose (deposited energy per unit of crystal mass) is needed to record data to the diffraction limit of the crystal. In practical terms, radiation damage prevents collection of full data from one micro-crystal or from one site on a large crystal. Fundamental studies of radiation damage may address this problem in part. At the energies typically used for macromolecular crystallography $(6-20 \mathrm{keV})$ and for the low $\mathrm{Z}$ elements that make up the bulk of the sample, the main mode of interaction is the absorption of an X-ray photon resulting in the emission of a high energy $(\mathrm{keV})$ photoelectron and low energy $(\sim 100 \mathrm{eV})$ Auger electrons. Primary damage occurs when these electrons scatter around in the crystal until they are absorbed after a distance of a $0.1 \mu \mathrm{m}$ for Auger electrons and $1-10 \mu \mathrm{m}$ for photoelectrons. If the beam or the crystal is sufficiently small, the photoelectron can escape the illuminated volume, reducing damage within that volume. A series of calculations predicted the magnitude of this effect [59], which has been experimentally demonstrated with a $1-\mu \mathrm{m}$ beam at $18.5 \mathrm{keV}[60,61]$. Although the damage was reduced for a given dose, the loss of diffraction from the smaller diffracting volume was greater than the loss in radiation sensitivity. Smaller beams and/or higher X-ray energies must be studied to determine whether photoelectron escape has a practical application in macromolecular crystallography. Alternatively, at low energies $(<6 \mathrm{keV})$ the increase absorption in the sample results in increased damage, and radiation damage may be reduced by using microcrystals [62]. The fundamental studies of radiation damage within and beyond the beam footprint showed that damage to a protein crystal from $18.5-\mathrm{keV}$ X-rays extended no more than $4 \mu \mathrm{m}$ beyond the center of a $1-\mu \mathrm{m}$ beam [60]. This result is of immediate practical use in micro-crystallography as the basis for estimating the size of a damaged zone or the minimum crystal translation required to expose an undamaged region of a crystal. In addition, the common practice of matching the beam size to the crystal size to reduce background has an advantage for microcrystals where the photoelectron can leave the crystal, resulting in reduced radiation damage.

\section{Damage-free crystallography with an X-ray free electron laser}

Initial feasibility experiments using the X-ray free-electron laser (XFEL) at the Linac Coherent Light Source (LCLS) hold the promise of damage-free crystallography. These experiments showed that a single $\mathrm{X}$-ray pulse of several tens to 100 femtoseconds duration can produce usable diffraction data from protein crystals containing as few as $10^{3}$ unit cells 
$[63,64,65,66]$. The technique is named "diffract before destroy" because the short X-ray pulse is diffracted before it destroys the crystal. To realize the promise of damage-free crystallography, several challenges related to the X-ray source, sample handling [67] and data processing must be addressed. Data processing is complicated by the lack of any fully recorded Bragg reflections in the "still" diffraction images, and by the lack of multiple images from each crystal $[68,69]$. A vast number of crystals is required to estimate the full intensity of each reflection from a set of observations of unknown partiality. Additionally, the beam properties are variable as the lasing process produces X-ray pulses with considerably greater variation in intensity (5-12\% RMSD), energy ( 8 eV RMSD), and band width ( $50 \mathrm{eV}$ FWHM) [70], compared to beams from conventional synchrotron sources (less than 1\% RMSD, $0.1 \mathrm{eV}$ RMSD and $0.5 \mathrm{eV}$ FWHM, respectively).

Nevertheless the success of initial experiments holds great promise to eventually deliver damage-free crystal structures, especially with the increased capacity brought by new XFEL sources coming on line in Japan (SACLA) and Europe (XFEL) and in planning in Switzerland (SwissFEL) and Korea (PAL XFEL), as reviewed elsewhere in this journal [71].

\section{The future}

The rapid technical progress and a growing number of spectacular scientific achievements in the last five years demonstrate that micro-crystallography is indeed the "new normal" in macromolecular crystallography. Nevertheless several challenges remain. Beamlines of the requisite stability for 5- $\mu \mathrm{m}$ diameter or smaller X-ray beams are difficult to develop, and especially challenging for retrofitting on older beamlines built to a different standard. Small samples and beams need powerful, rapid, automated methods to locate and center crystals in the beam. Automation is also key to monitoring and maintaining beamline robustness and stability, and to keeping clumsy human hands away from endstation hardware. Radiation damage is a perpetual challenge regardless of crystal cryo-protection. Fast-readout detectors may effectively extend the lifetime of room-temperature crystals by outrunning damage caused by diffusing free radicals. Through improved signal-to-noise, fast detectors also push the envelope toward even smaller and more weakly diffracting crystals. Smaller samples, hotter beams and more in situ experiments return us to an era of multi-crystal data sets, but in this era multi-crystal, ultra-high-redundancy data can be taken very quickly. There is a great need for sophisticated software to sift through many partial data sets from many crystals and to assemble complete merged data sets of the highest redundancy, taken from the most isomorphous subset of crystals, in their least damaged state. The need is especially acute for data taken at room temperature in in situ experiments. The challenges are substantial but not insurmountable and the future is bright - we will see more biology on more difficult systems with hotter, smaller beams that are delivered with great precision and controlled by sophisticated tools.

\section{Acknowledgments}

This work was supported by the US National Institutes of Health (Y1-CO-1020 and Y1-GM-1104 to RFF and JLS) and by the Targeted Proteins Research Program from MEXT, Japan (to MY). The authors thank Ruben Reininger (APS) for helpful discussions.

\section{References and recommended reading}

Papers of particular interest, published within the period of review, have been highlighted as:

- of special interest 
$\bullet$ of outstanding interest

1. Nave C. Matching X-ray source, optics and detectors to protein crystallography requirements. Acta Crystallogr. 1999; D55:1663-1668.

2. Duke EMH, Johnson LN. Macromolecular crystallography at synchrotron radiation sources: current status and future developments. Proc R Soc A. 2010; 466:3421-3452.

3. Evans G, Axford D, Waterman D, Owen RL. Macromolecular microcrystallography. Crystallography Rev. 2011; 17:105-142.

4. Sanishvili R, Nagarajan V, Yoder D, Becker M, Xu S, Corcoran S, Akey DL, Smith JL, Fischetti RF. A $7 \mu \mathrm{m}$ mini-beam improves diffraction data from small or imperfect crystals of macromolecules. Acta Crystallogr. 2008; D64:425-435.

5. Riekel C. Recent developments in microdiffraction on protein crystals. J Synchrotron Radiat. 2004; 11:4-6. [PubMed: 14646120]

••6. Moukhametzianov R, Burghammer M, Edwards PC, Petitdemange S, Popov D, Fransen M, McMullan G, Schertlera GFX, Riekel C. Protein crystallography with a micrometre-sized synchrotron-radiation beam. Acta Crystallogr. 2008; D64:158-166. The first use of a 1-micron beam to determine a protein crystal structure is described.

7. Cusack S, Belrhali H, Bram A, Burghammer M, Perrakis A, Riekel C. Small is beautiful: Protein micro-crystallography. Nat Struct Biol. 1998; 5 (Suppl):634-637. [PubMed: 9699611]

8. Perrakis A, Cipriani F, Castagna JC, Claustre L, Burghammer M, Riekel C, Cusack S. Protein microcrystals and the design of a microdiffractometer: Current experience and plans at EMBL and ESRF/ID13. Acta Crystallogr. 1999; D55:1765-1770.

••9. Evans G, Alianelli L, Burt M, Wagner A, Sawhney KJS. Diamond beamline I24: A flexible instrument for macromolecular micro-crystallography. AIP Conf Proc. 2007; 879:836-839. Diamond beamline I24 produces a micro-beam using the secondary-source approach.

10. Igarashi N, Ikuta K, Miyoshi T, Matsugaki N, Yamada Y, Yousef MS, Wakatsuki S. X-ray beam stabilization at BL-17A, the protein microcrystallography beamline of the Photon Factory. J Synchrotron Radiat. 2008; 15:292-295. [PubMed: 18421162]

$\bullet$ 11. Fischetti RF, Xu S, Yoder D, Becker M, Venugopalan N, Sanishvili R, Hilgart M, Stepanov S, Makarov O, Smith JL. Mini-beam collimator enables micro-crystallography experiments on standard beamlines. J Synchrotron Radiat. 2009; 16:217-225. APS beamlines 23ID-B and 23IDD produce micro-beams via the aperture approach. [PubMed: 19240333]

••12. Flot D, Mairs T, Giraud T, Guijarro M, Lesourd M, Rey V, van Brussel D, Morawe C, Borel C, Hignette O, Chavanne J, et al. The ID23-2 structural biology microfocus beamline at the ESRF. J Synchrotron Radiat. 2010; 17:107-118. ESRF beamline ID23-2 is dedicated to microcrystallography and uses the direct-focus approach to produce a micro-beam. [PubMed: 20029119]

••13. Hirata K, Ueno G, Nisawa A, Kawano Y, Hikima T, Shimizu N, Kumasaka T, Yumoto H, Tanaka T, Takahashi S, Ohashi H, et al. New micro-beam beamline at SPring-8, targeting at protein micro-crystallography. AIP Conf Proc. 2010; 1234:901-904. SPring-8 BL32-XU is the first beamline with a 1-micron beam dedicated to macromolecular crystallography. The microbeam is produced via the divergence- limited source approach.

14. Kawano Y, Shimizu N, Baba S, Hasegawa K, Makino M, Mizuno N, Hoshino T, Ito R, Wada I, Hirata K, Ueno G, et al. Present status of SPring-8 macromolecular crystallography beamlines. AIP Conf Proc. 2010; 1234:359-362.

15. de Sanctis D, Beteva A, Caserotto H, Dobias F, Gabadinho J, Giraud T, Gobbo A, Guijarro M, Lentini M, Lavault B, Mairs T, et al. ID29: A high-intensity highly automated ESRF beamline for macromolecular crystallography experiments exploiting anomalous scattering. J Synchrotron Radiat. 2012; 19:455-461. [PubMed: 22514185]

16. Nelson R, Sawaya MR, Balbirnie M, Madsen AO, Riekel C, Grothe R, Eisenberg D. Structure of the cross-beta spine of amyloid-like fibrils. Nature. 2005; 435:773-778. [PubMed: 15944695]

17. Rasmussen SG, Choi HJ, Rosenbaum DM, Kobilka TS, Thian FS, Edwards PC, Burghammer M, Ratnala VR, Sanishvili R, Fischetti RF, Schertler GF, et al. Crystal structure of the human $\beta 2$ adrenergic G-protein-coupled receptor. Nature. 2007; 450:383-387. [PubMed: 17952055] 
18. Coulibaly F, Chiu E, Ikeda K, Gutmann S, Haebel PW, Schulze-Briese C, Mori H, Metcalf P. The molecular organization of cypovirus polyhedra. Nature. 2007; 446:97-101. [PubMed: 17330045]

19. Cherezov V, Rosenbaum DM, Hanson MA, Rasmussen SG, Thian FS, Kobilka TS, Choi HJ, Kuhn P, Weis WI, Kobilka BK, Stevens RC. High-resolution crystal structure of an engineered human $\beta 2$-adrenergic G protein-coupled receptor. Science. 2007; 318:1258-1265. [PubMed: 17962520]

20. Warne T, Serrano-Vega MJ, Baker JG, Moukhametzianov R, Edwards PC, Henderson R, Leslie AG, Tate CG, Schertler GF. Structure of a $\beta 1$-adrenergic G-protein-coupled receptor. Nature. 2008; 454:486-491. [PubMed: 18594507]

••21. Rasmussen SG, DeVree BT, Zou Y, Kruse AC, Chung KY, Kobilka TS, Thian FS, Chae PS, Pardon E, Calinski D, Mathiesen JM, et al. Crystal structure of the $\beta 2$ adrenergic receptor-Gs protein complex. Nature. 2011; 477:549-555. The structure for a long-sought signalling complex of a G-protein-coupled receptor with a heterotrimeric $\mathrm{G}$ protein is an example of the science enabled by micro-crystallography. [PubMed: 21772288]

22. Riekel C, Burghammer M, Schertler G. Protein crystallography microdiffraction. Curr Opin Struct Biol. 2005; 15:556-562. [PubMed: 16168633]

23. Manglik A, Kruse AC, Kobilka TS, Thian FS, Mathiesen JM, Sunahara RK, Pardo L, Weis WI, Kobilka BK, Granier S. Crystal structure of the micro-opioid receptor bound to a morphinan antagonist. Nature. 2012; 485:321-326. [PubMed: 22437502]

24. Wu H, Wacker D, Mileni M, Katritch V, Han GW, Vardy E, Liu W, Thompson AA, Huang XP, Carroll FI, Mascarella SW, et al. Structure of the human kappa-opioid receptor in complex with JDTic. Nature. 2012; 485:327-332. [PubMed: 22437504]

25. Coulibaly F, Chiu E, Gutmann S, Rajendran C, Haebel PW, Ikeda K, Mori H, Ward VK, SchulzeBriese $\mathrm{C}$, Metcalf $\mathrm{P}$. The atomic structure of baculovirus polyhedra reveals the independent emergence of infectious crystals in DNA and RNA viruses. Proc Natl Acad Sci U S A. 2009; 106:22205-22210. [PubMed: 20007786]

26. Ji X, Sutton G, Evans G, Axford D, Owen R, Stuart DI. How baculovirus polyhedra fit square pegs into round holes to robustly package viruses. Embo J. 2010; 29:505-514. [PubMed: 19959989]

27. Laganowsky A, Liu C, Sawaya MR, Whitelegge JP, Park J, Zhao M, Pensalfini A, Soriaga AB, Landau M, Teng PK, Cascio D, et al. Atomic view of a toxic amyloid small oligomer. Science. 2012; 335:1228-1231. [PubMed: 22403391]

28. Emery L, Borland M. Progress towards top-up mode operations at the Advanced Photon Source. AIP Conf Proc. 2000; 521:409-414.

29. Tanaka H, Adachi M, Aoki T, Asaka T, Baron A, Date S, Fukami K, Furukawa Y, Hanaki H, Hosoda N, Ishikawa T, et al. Stable top-up operation at SPring-8. J Synchrotron Radiat. 2006; 13:378-391. [PubMed: 16924134]

30. Yamazaki H, Shimizu Y, Miura T, Tanaka M, Kishimoto H, Matsuzaki Y, Shimizu N, Kawano Y, Kumasaka T, Yamamoto M, Koganezawa T, et al. Improvement in stability of SPring-8 standard X-ray monochromators with water-cooled crystals. AIP Conf Proc. 2010; 1234:785-788.

31. Fischetti R, Stepanov S, Rosenbaum G, Barrea R, Black E, Gore D, Heurich R, Kondrashkina E, Kropf AJ, Wang S, Zhang K, et al. The BioCAT undulator beamline 18ID: A facility for biological non-crystalline diffraction and X-ray absorption spectroscopy at the Advanced Photon Source. J Synchrotron Radiat. 2004; 11:399-405. [PubMed: 15310956]

32. Bunk O, Pfeiffer F, Stampanoni M, Patterson BD, Schulze-Briese C, David C. X-ray beamposition monitoring in the sub-micrometre and sub-second regime. J Synchrotron Radiat. 2005; 12:795-799. [PubMed: 16239750]

33. Tucoulou R, Martinez-Criado G, Bleuet P, Kieffer I, Cloetens P, Laboure S, Martin T, Guilloud C, Susini J. High-resolution angular beam stability monitoring at a nanofocusing beamline. J Synchrotron Radiat. 2008; 15:392-398. [PubMed: 18552433]

34. Xu S, Makarov O, Benn R, Yoder DW, Stepanov S, Becker M, Corcoran S, Hilgart M, Nagarajan V, Ogata C, Pothineni S, et al. Micro-crystallography developments at GM/CA CAT at the APS. AIP Conf Proc. 2010; 1234:905-908.

35. Yoder DW, Makarov O, Corcoran S, Fischetti RF. PID feedback control of monochromator thermal stabilization. Nucl Instr Meth Phys Res Sec A. 2011; 649:107-108. 
36. Pauluhn A, Pradervand C, Rossetti D, Salathe M, Schulze-Briese C. Automatic loop centring with a high-precision goniometer head at the SLS macromolecular crystallography beamlines. J Synchrotron Radiat. 2011; 18:595-600. [PubMed: 21685676]

37. Hilgart MC, Sanishvili R, Ogata CM, Becker M, Venugopalan N, Stepanov S, Makarov O, Smith JL, Fischetti RF. Automated sample-scanning methods for radiation damage mitigation and diffraction-based centering of macromolecular crystals. J Synchrotron Radiat. 2011; 18:717-722. [PubMed: 21862850]

38. Aishima J, Owen RL, Axford D, Shepherd E, Winter G, Levik K, Gibbons P, Ashton A, Evans G. High-speed crystal detection and characterization using a fast-readout detector. Acta Crystallogr. 2010; D66:1032-1035.

39. Bowler MW, Guijarro M, Petitdemange S, Baker I, Svensson O, Burghammer M, MuellerDieckmann C, Gordon EJ, Flot D, McSweeney SM, Leonard GA. Diffraction cartography: Applying microbeams to macromolecular crystallography sample evaluation and data collection. Acta Crystallogr. 2010; D66:855-864.

40. Cohen AE, Ellis PJ, Miller MD, Deacon AM, Phizackerley RP. An automated system to mount cryo-cooled protein crystals on a synchrotron beamline, using compact sample cassettes and a small-scale robot. J Appl Cryst. 2002; 35:720-726.

41. Snell G, Cork C, Nordmeyer R, Cornell E, Meigs G, Yegian D, Jaklevic J, Jin J, Stevens RC, Earnest T. Automated sample mounting and alignment system for biological crystallography at a synchrotron source. Structure. 2004; 12:537-545. [PubMed: 15062077]

42. Cipriani F, Felisaz F, Launer L, Aksoy JS, Caserotto H, Cusack S, Dallery M, di-Chiaro F, Guijarro M, Huet J, Larsen S, et al. Automation of sample mounting for macromolecular crystallography. Acta Crystallogr. 2006; D62:1251-1259.

43. Jacquamet L, Joly J, Bertoni A, Charrault P, Pirocchi M, Vernede X, Bouis F, Borel F, Perin JP, Denis T, Rechatin JL, et al. Upgrade of the CATS sample changer on FIP-BM30A at the ESRF: Towards a commercialized standard. J Synchrotron Radiat. 2009; 16:14-21. [PubMed: 19096169]

44. Murakami H, Ueno G, Shimizu N, Kumasaka T, Yamamoto M. Upgrade of automated sample exchanger SPACE. J Appl Cryst. 2012; 45:234-238.

45. Pohl E, Ristau U, Gehrmann T, Jahn D, Robrahn B, Malthan D, Dobler H, Hermes C. Automation of the EMBL Hamburg protein crystallography beamline BW7B. J Synchrotron Radiat. 2004; 11:372-377. [PubMed: 15310952]

46. Yoder DW, Sanishvili R, Vogt S, Xu S, Makarov O, RB, Corcoran S, Fischetti RF. One-micron beams for macromolecular crystallography at GM/CA CAT. AIP Conf Proc. 2010:419-422.

47. Xu S, Keefe LJ, Mulichak A, Yan L, Alp EE, Zhao J, Fischetti RF. Mini-beam collimator applications at the Advanced Photon Source. Nucl Instr Meth Phys Res Sec A. 2011; 649:104 106.

48. Yamauchi K, Mimura H, Inagaki K, Mori Y. Figuring with subnanometer-level accuracy by numerically controlled elastic emission machining. Rev Sci Instrum. 2002; 73:4028-4033.

49. Mimura H, Matsuyama S, Yumoto H, Hara H, Yamamura K, Sano Y, Shibahara M, Endo K, Mori H, Nishino Y, Tamasaku K, et al. Hard X-ray diffraction-limited nanofocusing with KirkpatrickBaez mirrors. Japanese Journal of Applied Physics. 2005; 44:L539-L542.

50. Caffrey M. Crystallizing membrane proteins for structure determination: Use of lipidic mesophases. Annu Rev Biophys. 2009; 38:29-51. [PubMed: 19086821]

51. Caffrey M. Crystallizing membrane proteins for structure-function studies using lipidic mesophases. Biochem Soc Trans. 2011; 39:725-732. [PubMed: 21599641]

52. Cherezov V, Hanson MA, Griffith MT, Hilgart MC, Sanishvili R, Nagarajan V, Stepanov S, Fischetti RF, Kuhn P, Stevens RC. Rastering strategy for screening and centring of microcrystal samples of human membrane proteins with a sub-10 micron size X-ray synchrotron beam. J R Soc Interface. 2009; 6 (Suppl 5):S587-597. [PubMed: 19535414]

53. Bingel-Erlenmeyer R, Olieric V, Grimshaw JPA, Gabadinho J, Wang X, Ebner SG, Isenegger A, Schneider R, Schneider J, Glettig W, Pradervand C, et al. SLS crystallization platform at beamline X06DA-A fully automated pipeline enabling in situ X-ray diffraction screening. Crystal Growth Design. 2011; 11:916-923. 
54. Axford D, Owen RL, Aishima J, Foadi J, Morgan AW, Robinson JI, Nettleship JE, Owens RJ, Moraes I, Fry EE, Grimes JM, et al. In situ macromolecular crystallography using microbeams. Acta Crystallogr. 2012; D68:592-600.

•55. Wang X, Peng W, Ren J, Hu Z, Xu J, Lou Z, Li X, Yin W, Shen X, Porta C, Walter TS, et al. A sensor-adaptor mechanism for enterovirus uncoating from structures of EV71. Nat Struct Mol Biol. 2012; 19:424-429. The first report of structures solved with data collected from microcrystals in situ may be a harbinger of future micro-crystallography. [PubMed: 22388738]

-56. Owen RL, Axford D, Nettleship JE, Owens RJ, Robinson JI, Morgan AW, Dore AS, Lebon G, Tate CG, Fry EE, Ren J, et al. Outrunning free radicals in room-temperature macromolecular crystallography. Acta Crystallogr D Biol Crystallogr. 2012; 68:810-818. The ability to "outrun" radiation damage in room-temperature crystals by use of a fast-readout detector is demonstrated experimentally. [PubMed: 22751666]

57. Warkentin M, Badeau R, Hopkins J, Thorne RE. Dark progression reveals slow timescales for radiation damage between $\mathrm{T}=180$ and $240 \mathrm{~K}$. Acta Crystallogr D Biol Crystallogr. 2011; 67:792803. [PubMed: 21904032]

-58. Liu Q, Dahmane T, Zhang Z, Assur Z, Brasch J, Shapiro L, Mancia F, Hendrickson WA. Structures from anomalous diffraction of native biological macromolecules. Science. 2012; 336:1033-1037. Multi-crystal data sets were used to enhance weak anomalous phasing signals. The work illustrates the usefulness of high-redundancy, multi-crystal data sets, as are increasingly common in micro-crystallography. [PubMed: 22628655]

59. Cowan JA, Nave C. The optimum conditions to collect X-ray data from very small samples. J Synchrotron Radiat. 2008; 15:458-462. [PubMed: 18728316]

-60. Sanishvili R, Yoder DW, Pothineni SB, Rosenbaum G, Xu S, Vogt S, Stepanov S, Makarov OA, Corcoran S, Benn R, Nagarajan V, et al. Radiation damage in protein crystals is reduced with a micron-sized X-ray beam. Proc Natl Acad Sci U S A. 2011; 108:6127-6132. The first experimental demonstration of photoelectron damage outside the micro-beam footprint on a protein crystal shows that damage from $18.5 \mathrm{keV}$ X-rays extends only about $4 \mu \mathrm{m}$ through the crystal. [PubMed: 21444772]

61. Finfrock YZ, Stern EA, Yacoby Y, Alkire RW, Evans-Lutterodt K, Stein A, Isakovic AF, Kas JJ, Joachimiak A. Spatial dependence and mitigation of radiation damage by a line-focus mini-beam. Acta Crystallogr. 2010; D66:1287-1294.

62. Paithankar KS, Garman EF. Know your dose: RADDOSE. Acta Crystallogr. 2010; D66:381-388.

63. Chapman HN, Fromme P, Barty A, White TA, Kirian RA, Aquila A, Hunter MS, Schulz J, DePonte DP, Weierstall U, Doak RB, et al. Femtosecond X-ray protein nanocrystallography. Nature. 2011; 470:73-77. [PubMed: 21293373]

64. Aquila A, Hunter MS, Doak RB, Kirian RA, Fromme P, White TA, Andreasson J, Arnlund D, Bajt $\mathrm{S}$, Barends TR, Barthelmess M, et al. Time-resolved protein nanocrystallography using an X-ray free-electron laser. Opt Express. 2012; 20:2706-2716. [PubMed: 22330507]

65. Johansson LC, Arnlund D, White TA, Katona G, Deponte DP, Weierstall U, Doak RB, Shoeman RL, Lomb L, Malmerberg E, Davidsson J, et al. Lipidic phase membrane protein serial femtosecond crystallography. Nat Methods. 2012; 9:263-265. [PubMed: 22286383]

66. Boutet S, Lomb L, Williams GJ, Barends TR, Aquila A, Doak RB, Weierstall U, Deponte DP, Steinbrener J, Shoeman RL, Messerschmidt M, et al. High-resolution protein structure determination by serial femtosecond crystallography. Science. 2012

67. Weierstall U, Spence JC, Doak RB. Injector for scattering measurements on fully solvated biospecies. Rev Sci Instrum. 2012; 83:035108. [PubMed: 22462961]

68. Hunter MS, Fromme P. Toward structure determination using membrane-protein nanocrystals and microcrystals. Methods. 2011; 55:387-404. [PubMed: 22197730]

69. Kirian RA, White TA, Holton JM, Chapman HN, Fromme P, Barty A, Lomb L, Aquila A, Maia FR, Martin AV, Fromme R, et al. Structure-factor analysis of femtosecond microdiffraction patterns from protein nanocrystals. Acta Crystallogr. 2011; A67:131-140.

70. Emma P, Akre R, Arthur J, Bionta R, Bostedt C, Bozek J, Brachmann A, Bucksbaum P, Coffee R, Decker F-J, Ding Y, et al. First lasing and operation of an ångstrom-wavelength free-electron laser. Nature Photonics. 2010; 4:641-647. 
71. Neutze R, Moffat JK. Ultrafast crystallography with X-ray free electron lasers. Curr Opin Struct Biol. 2012:22.

72. Alkire RW, Molitsky M, Rotella FJ, Lazarski K, Joachimiak A. A new mini-beam device for protein crystallography. Nucl Instr Meth Phys Res Sec A. 2011; 649:112-113.

73. Gillilan RE, Cook MJ, Cornaby SW, Bilderback DH. Microcrystallography using single-bounce monocapillary optics. J Synchrotron Radiat. 2010; 17:227-236. [PubMed: 20157276]

74. Liu Z, Xu S, Yoder D, Fischetti RF. Simulation and optimization of a sub-micron beam for macromolecular crystallography using SHADOW and XOP at GM/CA CAT at the APS. Proc SPIE. 201110.1117/12.894173:10.1117/12.894173

75. Berman LE, Allaire M, Chance MR, Hendrickson WA, Heroux A, Jakoncic J, Liu Q, Orville AM, Robinson HH, Schneider DK, Shi W, et al. Optics concept for a pair of undulator beamlines for MX. Nucl Instr Meth Phys Res Sec A. 2011; 649:131-135. 


\section{Highlights}

- X-ray micro-beams permit structure determination from small or imperfect crystals

- Robust micro-beams require source, optics and sample support to be extremely stable

- Four different approaches to making a 1-20-micron beam have been implemented

- A growing demand has led to $\sim 20$ beamlines for micro-crystallography worldwide

- Micro-beams enable data collection from LCP-grown crystals and crystals in situ 
Focus

(a)

(b)

(c)

(d)

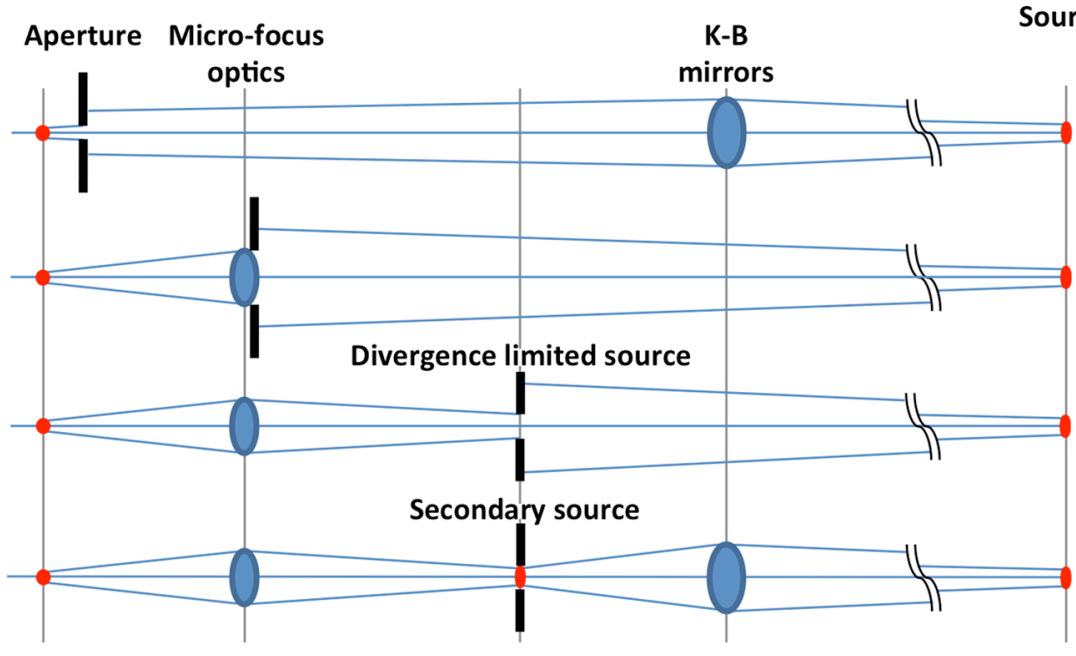

Figure 1. Approaches to making a small beam for micro-crystallography

(a) Aperture approach. The full central cone from the undulator source is focused by the mirrors and the beam size is defined with an aperture near the sample, typically $30 \mathrm{~mm}$ upstream. (b) Direct focus approach. Short mirrors near the sample capture a portion of the central cone from the undulator source and focus the beam directly to the sample position. (c) Divergence-limited source approach. A portion of the undulator central cone is selected by slits, which are imaged at the sample position by micro-focusing optics near the sample. (d) Secondary source approach. Upstream mirrors focus the full central cone of the undulator onto a set of slits. A second set of optics near the sample images the slits to the sample position. The beam direction is right to left. Focusing optics are depicted as blue ellipses, the source and focal points as red dots, and apertures and slits as black bars. 


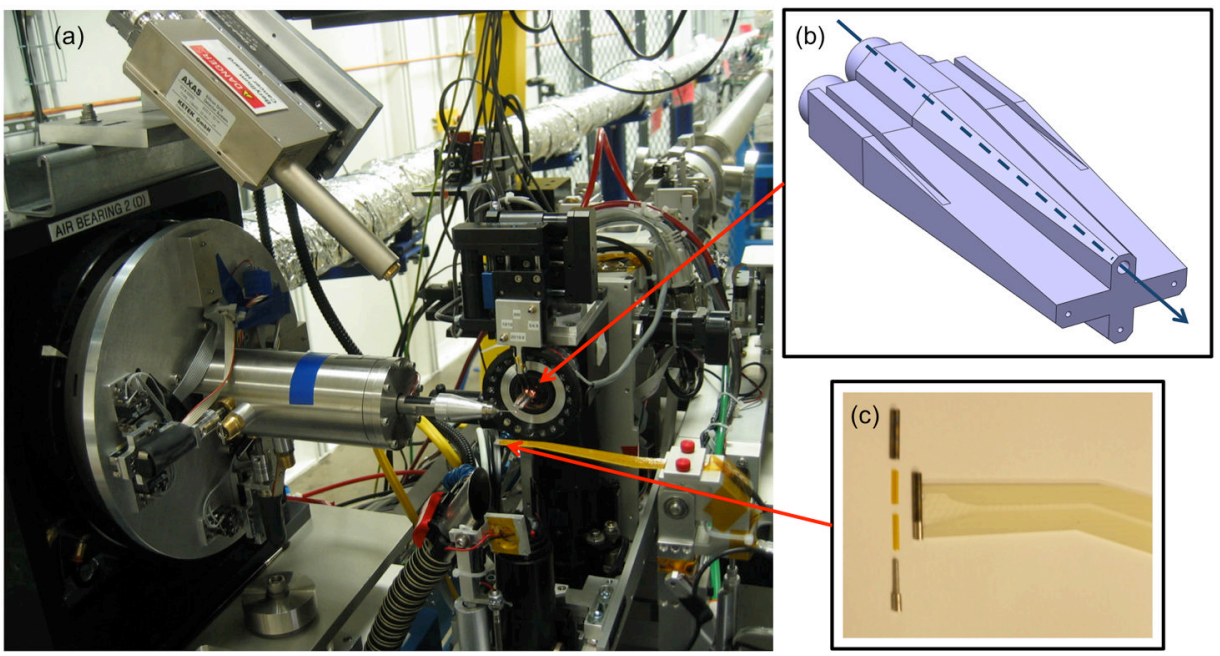

Figure 2. Micro-crystallography endstation at APS beamline 23ID-B

(a) Sample environment. The sample is mounted on an air-bearing goniometer with $1-\mu \mathrm{m}$ peak-to-peak SOC [34]. The mini-beam quad collimator is positioned downstream of the high-resolution microscope that views the sample along the beam axis. The active beam stop is mounted from the right. A fluorescence detector is mounted in the upper left. The sample cryo-cooler, usually mounted in the upper right, is removed in this photograph. (b) Minibeam quad collimator. In this schematic, the beam vector passes through the scatter guard aperture. Apertures in the other beam paths define 5-, 10- and 20- $\mu \mathrm{m}$ diameter beams. (c) Active beamstop. The beamstop is shown before (left) and after (right) assembly. X-rays impinge on the beamstop and eject photoelectrons, which yield a current that is linearly proportional to the incident intensity [34]. 
(a)

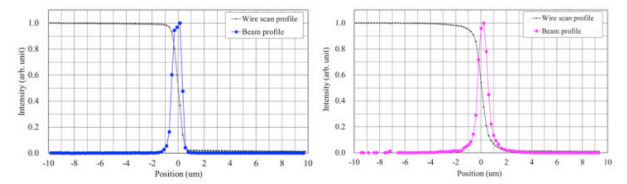

(b)
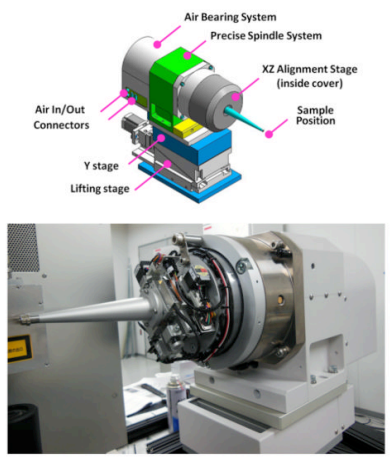

(c)

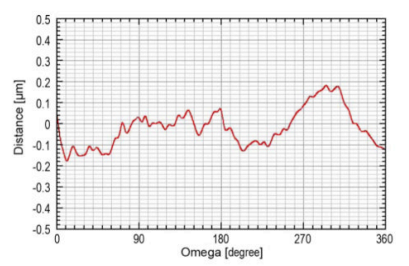

Figure 3. SPring-8 BL32XU micro-focus beamline

(a) Focused beam profile at the sample position. The horizontal (left) and the vertical (right) beam profiles are from a wire scan. The FWHM of the focused beam is $0.9 \mu \mathrm{m}$ in both directions. (b) High-precision air-bearing Kohzu QKSU-1 goniometer, shown in a schematic drawing (top) and photograph (bottom). The QKSU-0 goniometer is installed on beamlines BL17 and BL01 at the Photon Factory, and beamlines BL41XU and BL32XU at SPring-8. (c) Plot of the QKSU-1 SOC through $360^{\circ}$ rotation. The displacement of a precise ball on the horizontally mounted goniometer was measured with a capacitive sensor. (Drawing and inspection data courtesy of Kohzu Precision Co., Ltd.) 
Table 1

Micro-crystallography beamlines

\begin{tabular}{|c|c|c|c|}
\hline Facility \& beamline & Target beam size ${ }^{a}$ & Energy range & Approach \\
\hline \multicolumn{4}{|l|}{ Operating beamlines $b$} \\
\hline APS 23ID-B [11] & $5,10,20 \mu \mathrm{m}$ & $3.5-20 \mathrm{keV}$ & Aperture \\
\hline APS 23ID-D [11] & $5,10,20 \mu \mathrm{m}$ & $5-20 \mathrm{keV}$ & Aperture \\
\hline APS 17ID-B [47] & $10,20 \mu \mathrm{m}$ & $6-20 \mathrm{keV}$ & Aperture \\
\hline APS 19ID [72] & $5,10,20 \mu \mathrm{m}$ & $6-17 \mathrm{keV}$ & Aperture \\
\hline APS 24ID-E & $5-20 \mu \mathrm{m}$ & $12.66 \mathrm{keV}$ & Aperture \\
\hline APS 31ID & $20 \mu \mathrm{m}$ & $9-13.8 \mathrm{keV}$ & Aperture \\
\hline Australia MX2 & $10 \mu \mathrm{m}$ & $5.5-28 \mathrm{keV}$ & Aperture \\
\hline CHESS A1 [73] & $<20 \mu \mathrm{m}$ & $12.68 \mathrm{keV}$ & Direct focus \\
\hline CHESS F1 [73] & $<20 \mu \mathrm{m}$ & $13.50 \mathrm{kev}$ & Direct focus \\
\hline CHESS F2 [73] & $<20 \mu \mathrm{m}$ & $7-16 \mathrm{keV}$ & Direct focus \\
\hline Diamond I02 & $20 \mu \mathrm{m}$ & $5-25 \mathrm{keV}$ & Aperture \\
\hline Diamond I03 & $20 \mu \mathrm{m}$ & $5-25 \mathrm{keV}$ & Aperture \\
\hline Diamond I04 & $2 \times 8 \mu \mathrm{m}^{2}$ & $13.1,7.15 \mathrm{keV}$ & Aperture \\
\hline Diamond I24 [9] & $7-10 \mu \mathrm{m}$ & $6.5-18 \mathrm{keV}$ & Secondary source \\
\hline ESRF ID13 EHII [6] & $1 \mu \mathrm{m}$ & $5-17 \mathrm{keV}$ & Direct focus \\
\hline ESRF ID23-2 [12] & $10 \mu \mathrm{m}$ & $14.2 \mathrm{keV}$ & Direct focus \\
\hline ESRF ID29 [15] & $10,20 \mu \mathrm{m}$ & $6-20 \mathrm{keV}$ & Aperture \\
\hline Photon Factory BL-17A [10] & $20 \mu \mathrm{m}$ & $5.9-13.8 \mathrm{keV}$ & Aperture \\
\hline Photon Factory BL-1A & $10 \mu \mathrm{m}$ & $2.7-3.0 \mathrm{keV}$ & Aperture \\
\hline SPring-8 BL32XU [13] & $1-10 \mu \mathrm{m}$ & $8.5-20 \mathrm{keV}$ & Divergence-limited source \\
\hline SPring-8 BL41XU [14] & $10 \mu \mathrm{m}$ & $6.5-35 \mathrm{keV}$ & Aperture \\
\hline SLS X06SA & $(15) \times 5 \mu \mathrm{m}^{2}$ & $5.7-17.5 \mathrm{keV}$ & (Aperture) direct focus \\
\hline SSRL 12-2 & $7,10,20 \mu \mathrm{m}$ & $6.7-17.2 \mathrm{keV}$ & Aperture \\
\hline \multicolumn{3}{|l|}{ Beamlines in process } & Status \\
\hline ALBA BL13 & $300 \times 7 \mu \mathrm{m}^{2}$ & $5-21 \mathrm{keV}$ & Commissioning \\
\hline Diamond I02 & $20,10 \mu \mathrm{m}$ & $7-17 \mathrm{keV}$ & Commissioning \\
\hline Diamond I03 & $20,10 \mu \mathrm{m}$ & $7-17 \mathrm{keV}$ & Commissioning \\
\hline Diamond I04 & $20,10 \mu \mathrm{m}$ & $7-17 \mathrm{keV}$ & Commissioning \\
\hline PETRA III MX1 & $5,10 \mu \mathrm{m} ; 28 \times 13 \mu \mathrm{m}^{2}$ & $5-17 \mathrm{keV}$ & Commissioning \\
\hline PETRA III MX2 & $4 \times 1 \mu \mathrm{m}^{2}$ & $7-35 \mathrm{keV}$ & Commissioning \\
\hline APS 23ID-D [74] & $1-20 \mu \mathrm{m}$ & $6-35 \mathrm{keV}$ & Construction \\
\hline NSRRC PX & $1-50 \mu \mathrm{m}$ & $5.7-20 \mathrm{keV}$ & Construction \\
\hline SOLEIL PX2 & $20 \mu \mathrm{m}^{2}$ & $5-15 \mathrm{keV}$ & Construction \\
\hline SSRF NFPS & $10 \times 5 \mu \mathrm{m}^{2}$ & $5-18 \mathrm{keV}$ & Construction \\
\hline MAX IV BioMAX & $20 \mu \mathrm{m}$ & $5-25 \mathrm{keV}$ & Design \\
\hline
\end{tabular}




\begin{tabular}{|l|c|c|c|}
\hline Facility \& beamline & Target beam size $^{\boldsymbol{a}}$ & Energy range & Approach \\
\hline NSLS II FMX [75] & $1-100 \mu \mathrm{m}$ & $5-20 \mathrm{keV}$ & Design \\
\hline NSLS II AMX [75] & $5-300 \mu \mathrm{m}$ & $5-25 \mathrm{keV}$ & Design \\
\hline NSLS II NYX & $5-50 \mu \mathrm{m}$ & $3.5-17.5 \mathrm{keV}$ & Design \\
\hline
\end{tabular}

${ }^{a}$ All dimensions are FWHM. If two dimensions are listed, the first is the horizontal dimension and the second is the vertical (HxV). Several beamlines have selectable beam sizes, designated by comma-separated discrete sizes or by a size range.

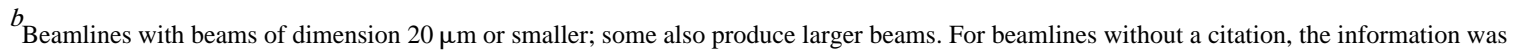
obtained from http://biosync.sbkb.org/index.jsp or from the beamline web site. 